\title{
Highly regioselective and chemoselective titanocene mediated Barbier-type allylation reactions $\dagger$
}

Cite this: Chem. Commun., 2014 50,2211

Received 4th December 2013, Accepted 24th December 2013

DOI: $10.1039 / c 3 c c 49230 c$

www.rsc.org/chemcomm

\author{
Sara P. Morcillo, ${ }^{a}$ Ángela Martínez-Peragón, ${ }^{a}$ Verena Jakoby, ${ }^{b}$ Antonio J. Mota, ${ }^{c}$ \\ Christian Kube, ${ }^{b}$ José Justicia, ${ }^{a}$ Juan M. Cuerva*a and Andreas Gansäuer*b
}

Titanocene carboxylate 1 is an excellent chemoselective reagent for unprecedented $\alpha$-regioselective Barbier-type reactions. It constitutes the first titanocene(III) able to tolerate epoxides and readily reduced carbonyl compounds, such as aromatic and $\alpha, \beta$-unsaturated aldehydes.

Titanocene(III) complexes are useful tools for mediating and catalyzing a number of useful transformations, ${ }^{1}$ such as homolytic epoxide opening, ${ }^{2}$ pinacol coupling reactions, ${ }^{3}$ and Barbier-type additions of allylic and propargylic halides or carbonates to carbonyl compounds. ${ }^{4}$ A drawback of these procedures is the lack of chemoselectivity in the electron transfer step. For this reason, aromatic and $\alpha, \beta$-unsaturated carbonyl compounds are usually unsuitable substrates in Barbier-type reactions. ${ }^{4}$ Here, we demonstrate that this shortcoming can be resolved in the case of complex $\mathbf{1}$ (Scheme 1) in the presence of $\mathrm{Mn}$ dust via complex 2a (Fig. 1).,

Gratifyingly, 3 and 4, model compounds for aromatic and $\alpha, \beta$-unsaturated aldehydes, reacted with 5 in the presence of complex $\mathbf{1}$ and Mn dust to exclusively yield $\alpha$-prenylated compounds $\mathbf{6}$ and 7. Thus, the highly useful $\alpha$-regioselectivity of prenylation noted earlier

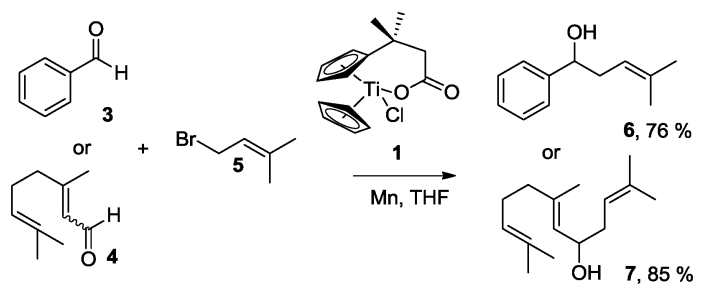

Scheme 1 Ti-mediated regioselective $\alpha$-prenylation of benzaldehyde (3) and citral (4).

\footnotetext{
${ }^{a}$ Department of Organic Chemistry, University of Granada, Fuentenueva Campus, Granada 18071, Spain. E-mail: jmcuerva@ugr.es

${ }^{b}$ Kekulé-Institut für Organische Chemie und Biochemie, Universität Bonn, GerhardDomagk-Strasse 1, 53121 Bonn, Germany. E-mail: andreas.gansaeuer@uni-bonn.de

${ }^{c}$ Department of Inorganic Chemistry, University of Granada, Fuentenueva Campus, Granada 18071, Spain

$\dagger$ Electronic supplementary information (ESI) available: Experimental methods and characterisation of new compounds. See DOI: $10.1039 / \mathrm{c} 3 \mathrm{cc} 49230 \mathrm{c}$
}

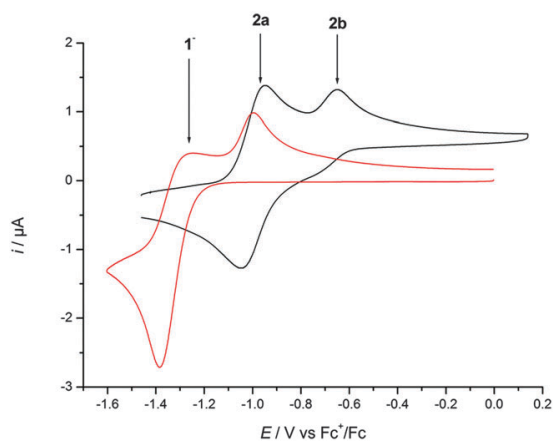

Fig. $1 \mathrm{CV}$ of $2 \mathrm{mM}$ solution of 1 (red) and $\mathrm{Mn}-1$ (black) recorded at $\nu=$ $100 \mathrm{mV} \mathrm{s}^{-1}$ in $0.2 \mathrm{M} \mathrm{TBAPF}_{6}-\mathrm{THF}$.

could be maintained. ${ }^{4,6}$ Remarkably, in the absence of 5, no pinacol products are formed. ${ }^{7}$ Further exploring this new reactivity concluded that epoxides were also tolerated by this reagent. This suggests that the aldehydes or epoxides cannot bind to Mn-1.

To rationalize these findings, cyclic voltammograms (CVs) of 1 and Mn-1 in THF were recorded (Fig. 1). The oxidation of electrochemically reduced $\mathbf{1}$ reveals the presence of two species. $\mathbf{1}^{-}\left(E_{\mathrm{pc}}=\right.$ $-1.38 \mathrm{~V} v \mathrm{~s} . \mathrm{Fc}^{+} / \mathrm{Fc}$ ) is formed via electron transfer at the electrode. The process is irreversible due to the formation of $2 \mathrm{a}\left(E_{\mathrm{pa} 1}=-1.00 \mathrm{~V}\right)$ through loss of chloride. For Mn-1, 2a $\left(E_{\mathrm{pa} 1}=-0.95 \mathrm{~V}\right)$ is formed as expected, due to the more efficient abstraction of the chloride and formation of $\mathrm{MnCl}_{2}$. The more negative value of $E_{\mathrm{pa} 1}$ compared to $\mathrm{Cp}_{2} \mathrm{TiCl}\left(E_{\mathrm{pa} 1}=-0.83 \mathrm{~V}\right)$ is in line with the carboxylate that is a better donor ligand than chloride. The second peak $\left(E_{\mathrm{pa} 2}=-0.65 \mathrm{~V}\right)$ is also observed at higher sweep rates $\left(\nu=1-50 \mathrm{~V} \mathrm{~s}^{-1}\right)$. Thus, the species being oxidized is an initial component ${ }^{8}$ of $\mathbf{M n}-\mathbf{1}$ in THF and is not formed during the sweep. We suggest that $\mathbf{2 b}$ and not cationic $2 \mathbf{c}$ is the second component of $\mathrm{Mn}-\mathbf{1}$ for a number of reasons. 2c should have a potential similar to that of $\left[\mathrm{Cp}\left(\mathrm{C}_{5} \mathrm{H}_{4}{ }^{t} \mathrm{Bu}\right) \mathrm{Ti}\right]^{+}\left(E_{\mathrm{pa}}=-0.47 \mathrm{~V}\right)$. It has been recently shown that cationic titanocene(III) complexes open epoxides. ${ }^{9}$ Both findings are in contradiction to the behavior of $\mathbf{M n - 1}$. In agreement with the observations, $\mathbf{2 b}$ is more difficult to oxidize than $2 \mathrm{a}$ because the electron density is withdrawn from $\mathrm{Ti}$ through carboxylate coordination. The steric shielding of Ti in $\mathbf{2 b}$ will 
be similar to that in $\mathbf{2 a}$ and thus epoxide and aldehyde binding is as difficult for $\mathbf{2 b}$ as for $2 \mathbf{a}$.
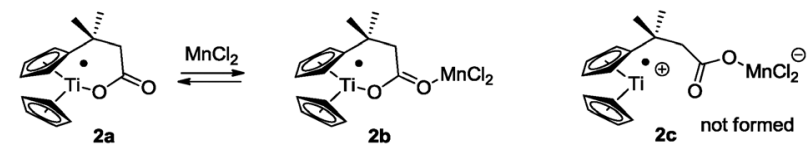

To understand the unprecedented chemoselectivity, we carried out the model reactions with Mn-reduced $\mathrm{Cp}_{2} \mathrm{TiCl}(\mathrm{OMe}){ }^{10}$ $\mathrm{Cp}_{2} \mathrm{TiCl}(\mathrm{OAc}){ }^{11}$ and $\mathrm{Cp}_{2} \mathrm{TiCl}(\mathrm{OBz}) .{ }^{12}$ Unselective electron transfer reactions with $\mathrm{Cp}_{2} \mathrm{TiCl}_{2}$ were observed. This suggests that the tethering of the carboxylate to the ligand is essential.

To highlight this point, the coordination of 2a to THF, benzaldehyde, and trimethyloxirane was studied by DFT calculations (Table 1). ${ }^{7}$

The generation of these coordination complexes is characterized by: (a) a only slightly negative enthaply of formation and (b) a highly unfavorable entropy of formation. This results in $\Delta G$ values of about +8 to $+12 \mathrm{kcal} \mathrm{mol}^{-1}$. $^{13}$ Therefore, aldehyde and epoxide complexation seems to be precluded as observed experimentally.

Next, we explored the chemoselectivity of electron transfer further (Scheme 2 and Table 2). Gratifyingly, our Barbier-type reactions using activated halides as pronucleophiles are general and take place with moderate to excellent yields. ${ }^{7}$ A variety of aromatic and $\alpha, \beta$-unsaturated aldehydes are suitable. Even acetophenone, as an example of aromatic ketones, is an excellent substrate (Scheme 2). All products are valuable building blocks for terpene synthesis. ${ }^{1 d}$ Even more interesting and

Table 1 Structures and energies of the interactions of THF, benzaldehyde (B), and trimethyloxirane (Ep) with 2a (for computational details see ESI, energies are in $\mathrm{kcal} \mathrm{mol}^{-1}$ )

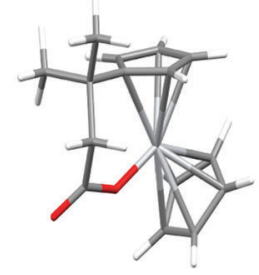

2a

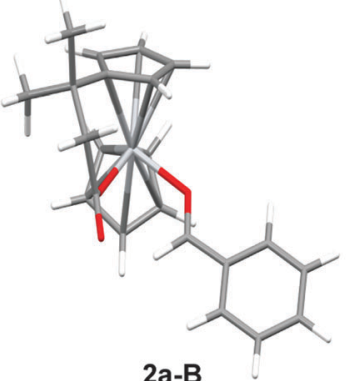

2a-B

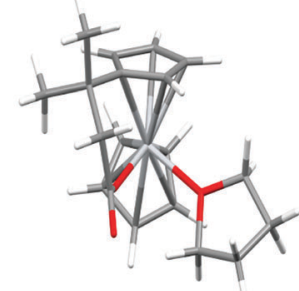

2a-THF

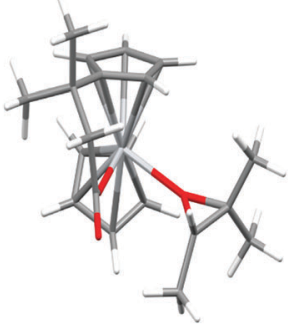

2a-Ep

\begin{tabular}{lrrr}
\hline Complex & \multicolumn{1}{c}{$\Delta H$} & $-T \Delta S$ & \multicolumn{1}{c}{$\Delta G$} \\
\hline 2a & 0.0 & 0.0 & 0.0 \\
2a-THF & -2.8 & +13.7 & +10.9 \\
2a-B & -4.2 & +12.5 & +8.3 \\
2a-Ep & -0.5 & +12.5 & +12.0
\end{tabular}
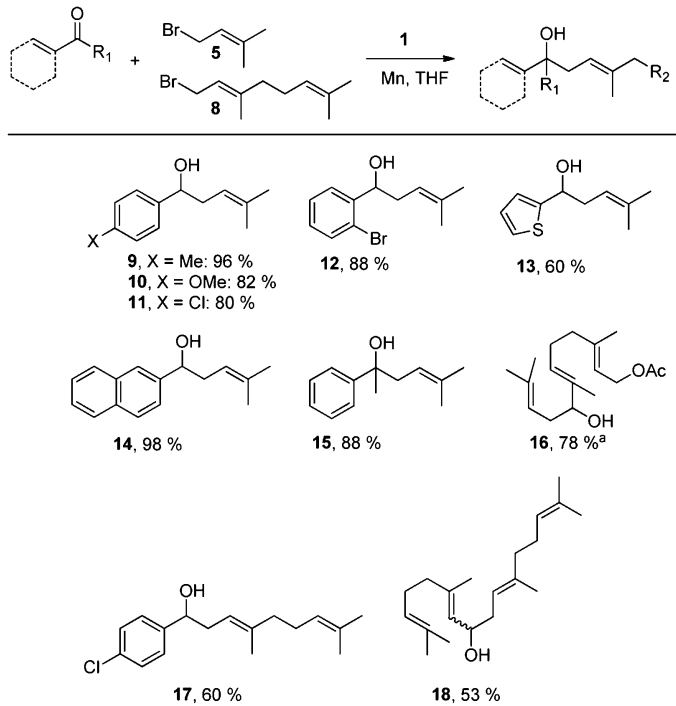

Scheme 2 Ti-mediated regioselective $\alpha$-prenylation of aromatic and $\alpha, \beta$-unsaturated carbonyl compounds. Conditions: for aromatic aldehydes: $1(1 \mathrm{mmol}), \mathrm{Mn}$ dust $(8 \mathrm{mmol})$, aldehyde $(1 \mathrm{mmol})$, and activated halide (2 mmol) in THF. Otherwise: $1(1.5 \mathrm{mmol}), \mathrm{Mn}$ dust $(8 \mathrm{mmol})$, carbonyl

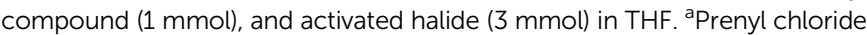
can be used with similar yield $(77 \%)$.

demanding are Barbier-type reactions with electrophiles (19-20) or nucleophiles (23), incorporating epoxides (Table 2).

In agreement with our DFT calculations, epoxides are readily tolerated by $\mathrm{Mn}-\mathbf{1}^{7}$ Thus, functionalized epoxypolyprenes that are highly attractive intermediates for synthesis of natural products ${ }^{1 d}$ can be prepared from either epoxide containing carbonyl compounds or activated halides. As an attractive additional feature, our novel method allows the elimination of the often difficult regioselective epoxidation step of the polyprenic starting materials.

An important aspect of this study is the regioselectivity of the addition of the allylic nucleophile. In contrast to the numerous $\gamma$-selective additions, $\alpha$-regioselective additions are considerably less common. ${ }^{14}$ Here, we obtained the $\alpha$-regioisomers in very high selectivity $(>92:<8)$ when prenyl derivatives 5,8 and 23 were used as pronucleophiles. Moreover, commercially available Mn dust could be used at room temperature.

Finally, we also investigated Wurtz-type coupling reactions mediated by $\mathrm{Mn}-1$. Such reactions can be carried out in the presence of $\mathrm{Cp}_{2}$ TiCl. ${ }^{15}$ However, the chemoselectivity of these reactions is low. This is not the case in our system and, hence, epoxide containing substrates can be readily coupled (Table 2 , entry 8 ). The reaction took place with excellent yield and also with a high $\alpha, \alpha$-regioselectivity (86:14).

In summary, we have demonstrated that Mn-1 is a reagent for Barbier-type allylation reactions delivering the $\alpha$-addition products with almost complete regioselectivity. The reactions proceed with an unprecedented chemoselectivity because epoxides and readily reduced carbonyl compounds, such as aromatic and $\alpha, \beta$-unsaturated aldehydes, are tolerated. The compounds obtained are difficult to prepare using other methodologies and are valuable substrates in terpene synthesis. Moreover, the reactions can be performed at room temperature and no preformed organometallic reagents (B or $\mathrm{Li}$ ) or especially activated metals (Ba) have to be employed. 
Table 2 Regioselective Barbier-type reactions of electrophiles and nucleophiles presenting an oxirane ring mediated by $\mathrm{Mn}-\mathbf{1}^{\mathrm{a}}$

Entry Carbonyl compound Halide

${ }^{a}$ Complex 1 (1.5 mmol), Mn dust (8 mmol), carbonyl compound $(1 \mathrm{mmol})$, and activated halide $(3 \mathrm{mmol})$ in THF. ${ }^{b}$ This compound was obtained as a $6: 1$ mixture of $\alpha, \alpha$ and $\alpha, \gamma$-regioisomers.

We thank the Spanish MICINN (Grants CTQ-2011.22455 and PRI-AIBDE-2011-1122) and SFB 813 'Chemistry at Spin Centers' for financial support. SPM thanks Regional Government of Andalucía for her contract. We also thank the Centro de Supercomputación de la Universidad de Granada (UGRGRID) for computational time.

\section{Notes and references}

1 (a) A. Gansäuer, T. Lauterbach and S. Narayan, Angew. Chem., Int. Ed., 2003, 42, 5556-5573; (b) J. M. Cuerva, J. Justicia, J. L. Oller-López and J. E. Oltra, Top. Curr. Chem., 2006, 264, 63-91; (c) A. Gansäuer, J. Justicia, C.-A. Fan, D. Worgull and F. Piestert, Top. Curr. Chem., 2007, 279, 25-52; (d) J. Justicia, L. Álvarez de Cienfuegos, A. G. Campaña, D. Miguel, V. Jakoby, A. Gansäuer and J. M. Cuerva, Chem. Soc. Rev., 2011, 40, 3525-3537.

2 For seminal work, see: (a) T. V. RajanBabu and W. A. Nugent, J. Am. Chem. Soc., 1994, 116, 986-997; (b) A. Gansäuer, H. Bluhm and M. Pierobon, J. Am. Chem. Soc., 1998, 120, 12849-12859.

3 (a) Y. Handa and J. Inanaga, Tetrahedron Lett., 1987, 28, 5717-5718; (b) A. Gansäuer, Chem. Commun., 1997, 457-458; (c) A. Gansäuer and
D. Bauer, J. Org. Chem., 1998, 63, 2070-2071; (d) A. Gansäuer and D. Bauer, Eur. J. Org. Chem., 1998, 2673-2676; (e) T. Hirao, B. Hatano, M. Asahara, Y. Muguruma and A. Ogawa, Tetrahedron Lett., 1998, 39, 5247-5248; $(f)$ M. C. Barden and J. Schwartz, J. Am. Chem. Soc., 1996, 118, 5484-5485; $(g)$ M. Paradas, A. G. Campaña, R. E. Estévez, L. Álvarez de Cienfuegos, T. Jiménez, R. Robles, J. M. Cuerva and J. E. Oltra, J. Org. Chem., 2009, 74, 3616-3619.

4 (a) R. E. Estévez, J. Justicia, B. Bazdi, N. Fuentes, M. Paradas, D. Choquesillo-Lazarte, J. M. García-Ruiz, R. Robles, A. Gansäuer, J. M. Cuerva and J. E. Oltra, Chem.-Eur. J., 2009, 15, 2774-2791; (b) A. G. Campaña, B. Bazdi, N. Fuentes, R. Robles, J. M. Cuerva, J. E. Oltra, S. Porcel and A. M. Echavarren, Angew. Chem., Int. Ed., 2008, 47, 7515-7519; (c) A. Millán, L. Álvarez de Cienfuegos, A. Martín-Lasanta, A. G. Campaña and J. M. Cuerva, Adv. Synth. Catal., 2011, 353, 73-78; (d) A. Martínez-Peragón, A. Millán, A. G. Campaña, I. Rodríguez-Márquez, S. Resa, D. Miguel, L. Álvarez de Cienfuegos and J. M. Cuerva, Eur. J. Org. Chem., 2012, 1499-1503; (e) J. Muñoz-Bascón, I. Sancho-Sanz, E. ÁlvarezManzaneda, A. Rosales and J. E. Oltra, Chem.-Eur. J., 2012, 18, 14479-14486.

5 (a) A. Gansäuer, D. Franke, T. Lauterbach and M. Nieger, J. Am. Chem. Soc., 2005, 127, 11622-11623; (b) A. Gansäuer, I. Winkler, D. Worgull, D. Franke, T. Lauterbach, A. Okkel and M. Nieger, Organometallics, 2008, 27, 5699-5707.

6 T. Jiménez, S. P. Morcillo, A. Martín-Lasanta, D. Collado-Sanz, D. J. Cárdenas, A. Gansäuer, J. Justicia and J. M. Cuerva, Chem.-Eur. J., 2012, 18, 12825-12833.

7 See $\mathrm{ESI} \dagger$ for details.

8 (a) R. J. Enemærke, G. H. Hjøllund, K. Daasbjerg and T. Skrydstrup, C. R. Acad. Sci., 2001, 4, 435-438; (b) R. J. Enemærke, J. Larsen, T. Skrydstrup and K. Daasbjerg, Organometallics, 2004, 23, 1866-1874; (c) R. J. Enemærke, J. Larsen, T. Skrydstrup and K. Daasbjerg, J. Am. Chem. Soc., 2004, 126, 7853-7864; (d) R. J. Enemærke, J. Larsen, G. H. Hjøllund, T. Skrydstrup and K. Daasbjerg, Organometallics, 2005, 24, 1252-1262; (e) J. Larsen, R. J. Enemærke, T. Skrydstrup and K. Daasbjerg, Organometallics, 2006, 25, 2031-2036; $(f)$ A. Gansäuer, A. Barchuk, F. Keller, M. Schmitt, S. Grimme, M. Gerenkamp, C. Mück-Lichtenfeld, K. Daasbjerg and H. Svith, J. Am. Chem. Soc., 2007, 129, 1359-1371; $(g)$ A. Gansäuer, K. Knebel, C. Kube, M. van Gastel, A. Cangönül, K. Daasbjerg, T. Hangele, M. Hülsen, M. Dolg and J. Friedrich, Chem.-Eur. J., 2012, 18, 2591-2599.

9 A. Cangönül, M. Behlendorf, A. Gansäuer and M. van Gastel, Inorg. Chem., 2013, 52, 11859-11866.

10 D. H. Gibson, Y. Ding, M. S. Mashuta and J. F. Richardson, Acta Crystallogr., Sect. C: Cryst. Struct. Commun., 1996, 559-560.

11 V. A. Knizhnikov, V. L. Shirokii and Y. A. Oldekop, Vestsi Akad. Navuk BSSR, Ser. Khim. Navuk, 1983, 3, 102-104.

12 B. S. Kaliral, J.-D. Foulon, T. A. Hamor, C. J. Jones, P. D. Beer and S. P. Fricker, Polyhedron, 1991, 10, 1847-1856.

13 A direct comparison of the binding capabilities of complex 2a with parent $\mathrm{Cp}_{2} \mathrm{TiCl}$ is not simple owing to that it is known that the chloride anion dissociates in THF solution generating cationic species (ref. 9). Such an effect cannot take place with a tethering ligand in complex 2. Related zwitterionic species $2 \mathrm{c}$ was obtained and the results showed that in the absence of a ligand (L) the zwitterion is too high in energy to be a real intermediate, as CV experiments suggest. In the presence of a ligand, cationic complex 2c-L was found to be thermodynamically highly disfavoured species.

14 (a) P. Girard, J. L. Namy and H. B. Kagan, J. Am. Chem. Soc., 1980, 102, 2693-2698; (b) B.-S. Guo, W. Doubleday and T. Cohen, J. Am. Chem. Soc., 1987, 109, 4710-4711; (c) A. Yanagisawa, S. Habaue, K. Yasue and H. Yamamoto, J. Am. Chem. Soc., 1994, 116, 6130-6141; (d) S. Matsukawa, Y. Funabashi and T. Imamoto, Tetrahedron Lett., 2003, 44, 1007-1010; (e) K. M. Depew, S. J. Danishefsky, N. Rosen and L. Sepp-Lorenzino, J. Am. Chem. Soc., 1996, 118, 12463-12464; $(f)$ B. Y. Park, T. P. Montgomery, V. J. Garza and M. J. Krische, J. Am. Chem. Soc., 2013, 135, 16320-16323.

15 (a) A. F. Barrero, M. M. Herrador, J. F. Quilez del Moral, P. Arteaga, J. F. Arteaga, M. Piedra and E. M. Sanchez, Org. Lett., 2005, 7, 2301-2304; (b) A. Millán, A. G. Campaña, B. Bazdi, D. Miguel, L. Álvarez de Cienfuegos, A. M. Echavarren and J. M. Cuerva, Chem.-Eur. J., 2011, 17, 3985-3994. 